\title{
Interference of Detection Rate of Lumbar Disc Herniation by Socioeconomic Status
}

\author{
Gyu Yeul Ji ${ }^{1}$, Chang Hyun $\mathrm{Oh}^{1,2}$, Nak-Yong Jung ${ }^{3}$, Seong Dae $\mathrm{An}^{1}$, Won-Seok $\mathrm{Choi}^{1}$, Jung Hoon Kim ${ }^{1}$ \\ ${ }^{1}$ Department of Neurosurgery, Guro Teun Teun Hospital, Seoul, Korea \\ ${ }^{2}$ Seoul Regional Military Manpower Administration, Seoul, Korea \\ ${ }^{3}$ Department of Orthopedic Surgery, Guro Teun Teun Hospital, Seoul, Korea
}

\begin{abstract}
Study Design: Retrospective study.
Purpose: The objective of the study is to evaluate the relationship between the detection rate of lumbar disc herniation and socioeconomic status.

Overview of Literature: Income is one important determinant of public health. Yet, there are no reports about the relationship between socioeconomic status and the detective rate of disc herniation.

Methods: In this study, 443 cases were checked for lumbar computed tomography for lumbar disc herniation, and they reviewed questionnaires about their socioeconomic status, the presence of back pain or radiating pain and the presence of a medical certificate (to check the medical or surgical treatment for the pain) during the Korean conscription.

Results: Without the consideration for the presence of a medical certificate, there was no difference in spinal physical grade according to socioeconomic status $(p=0.290)$. But, with the consideration of the presence of a medical certificate, the significant statistical differences were observed according to socioeconomic status in 249 cases in the presence of a medical certificate $(p=0.028)$. There was a lower detection rate in low economic status individuals than those in the high economic class. The common reason for not submitting a medical certificate is that it is neither necessary for the people of lower socioeconomic status nor is it financially affordable. Conclusions: The prevalence of lumbar disc herniation is not different according to socioeconomic status, but the detective rate was affected by socioeconomic status. Socioeconomic status is an important factor for detecting lumbar disc herniation.
\end{abstract}

Keywords: Herniated disc; Prevalence; Socioeconomic status; Conscription

\section{Introduction}

It is common sense that income is one important determinant of health among the various socioeconomic factors that can determine the health of a population [1]. Many studies have proven that low income has had a negative impact on population health $[2,3]$. This tendency also may involve the detection rate of the disease.
A lumbar disc herniation is also medical condition could affected by socioeconomic factors. For a correct diagnosis, a few specific radiological images are needed and sometimes some operational treatments should also be applied. Thus, the financial problem can interfere with the diagnosis of lumbar disc herniation. Unfortunately, however, there were no studies about the relationship between socioeconomic status and the detection rate of

Received Sep 3, 2011; Revised Dec 19, 2012; Accepted Dec 27, 2012

Corresponding author: Chang Hyun $\mathrm{Oh}$

Department of Neurosurgery, Guro Teun Teun Hospital,

1126-34 Guro 3-dong, Guro-gu, Seoul 152-053, Korea

Tel: +82-70-7780-4245, Fax: +82-2-851-9733, E-mail: dhckdgus@gmail.com 
disc herniation. We can only assume that there could be a strong relation. Herein, the authors researched in order to better understand the relationship between the detection rate of lumbar disc herniation and socioeconomic status, and to suggest the direction of a health care policy.

\section{Materials and Methods}

Since Korea has adopted the conscription system, all men are examined for the conscription at the Military Manpower Administration when they are over the age of 18 . All examinees with a disease should submit their medical certificate regarding their disease. The financial problem could interfere with the diagnosis of lumbar disc herniation by the high cost of radiologic imaging or physiologic studies. So, a medical certificate could be a barrier of the financial problem regarding the conscripted examinees. However, the physicians can check the imaging studies without additional costs during the conscription. So, the economic barrier to diagnose lumbar disc herniation could be absent for the intended duration. This survey was conducted at the Military Manpower Administration in Seoul as a retrospective human volunteer study.

Time duration of the data collection was 21 months from June 2009 to April 2011. During this period, authors checked for the presence of back pain or radiating pain. In this study, the inclusion criteria were the presence of back pain or radiating pain, and the agreement with the volunteers. Exclusion criteria were malingering examinees that experienced pain, the presence of lower extremities operation history, the disagreement concerning image findings between two observers, and the abnormal result of the Korean military personal inventory test. The other spinal diseases including ankylosing spondylitis, spondylolisthesis, spondylolysis, Shermann's nodules, limbus fractures, lumbarization and scoliosis were also excluded in this study. During the conscription, a total of 443 cases were included in this study. Among them, 248 were handed in with the medical certificate consisting of the medical records of lumbar disc herniation, and 195 were volunteers who were suffering from back pain. All subjects filled in brief questionnaires regarding socioeconomic status by familial monthly income, the presence of back pain or radiating pain, and the reason why they could not submit a medical certificate (in the cases with back pain history, but without a medical certificate). All cases were checked for lumbar computed tomography to examine lumbar disc herniation, and the authors reviewed the questionnaires.

Socioeconomic status was categorized into 3 groups according to their familial monthly incomes. According to the announcement of the Korean government, the Korean average income was 3,729,000 won per month in 2010. The authors defined the income of high economic class as more than 6,000,000 won per month, middle economic class as 2,000,000 to $6,000,000$ won per month, and low economic class as less than 2,000,000 won per month. To determine the economic status of the 18-years-old examinees, the monthly income of their parents were put into account.

The presence of back pain or radiating pain is defined as the symptom which presented at the most severe status. For example, if the examinees were in an operated status, the presence of back pain or radiating pain was verified as the moment of the most severe status without considering the operation.

By the Korean military service law, lumbar disc herniation was categorized into 5 physical grades (Table 1). The only preoperative herniation severity was considered to confirm the physical grade, and the presence of simple discectomy or spinal procedure was not considered to confirm the physical grade. In the schematic review, the Military Manpower Administration physical grade 1 is considered as normal, physical grade 2 as mild herniation, physical grade 3 as moderate herniation, physical grade 4 as severe herniation, and physical grade 5 as very severe herniation. In this study, 13 examinees were of an operated status, and the preoperative image study was only used for physical grade, and checked computed tomography was used to confirm the operation. The physical grade of each case was determined after discussions with a radiologist, an orthopedic surgeon, and a neurosurgeon.

This study was conducted with the approval of the committee in the Military Manpower Administration in Seoul. Evaluation of the statistical significance of difference between the groups was carried out using chi-square tests. Tests were considered significant at $p$-values of less than 0.05. Statistical comparisons were analyzed with SPSS ver. 12.0 (SPSS Inc., Chicago, IL, USA).

\section{Results}

A total of 443 cases were included in this study during 
Table 1. The Korean military service law about spinal disc herniation.

\begin{tabular}{|c|c|c|}
\hline Status of lumbar disc herniation & Physical grade & Severity \\
\hline Normal disc & 1 & Normal \\
\hline Mild disc bulging without compression of thecal sac & 2 & Mild \\
\hline Disc protrusion or extrusion without compression of thecal sac & 3 & Moderate \\
\hline Disc protrusion or extrusion with compression of thecal sac ${ }^{\text {a) }}$ & 4 & Severe \\
\hline Disc protrusion or extrusion with spinal canal compromise more than $50 \%{ }^{\mathrm{b})}$ & 5 & Very severe \\
\hline Disc protrusion or extrusion with positive cut-off sign ${ }^{c l}$ & 5 & Very severe \\
\hline
\end{tabular}

${ }^{a}$ Positive result of electromyogram test was defined as matched radiculopathy finding according to suspicious level of herniation; ${ }^{\text {b) }}$ spinal canal stenosis was defined as the narrowing of the spinal canal more than $50 \%$ of mid-sagittal diameter (front to back) in the same plane of imaging study; ${ }^{c}$ cut-off sign was defined as all loss of signal in neuromuscular at the interesting level using imaging study.

Table 2. The presence of the medical certificate, back pain, and radiating pain among 443 cases

\begin{tabular}{|c|c|c|c|c|}
\hline \multirow{2}{*}{ Category } & \multicolumn{4}{|c|}{ Physical grade by Korean Military Service Law } \\
\hline & Grade 1-2 & Grade 3 & Grade 4-5 & Total \\
\hline \multicolumn{5}{|c|}{ Presence of medical certificate } \\
\hline Yes & 18 & 50 & 178 & 246 \\
\hline No & 88 & 59 & 50 & 197 \\
\hline \multicolumn{5}{|l|}{ Experience of back pain } \\
\hline Yes & 88 & 108 & 226 & 422 \\
\hline No & 18 & 1 & 2 & 21 \\
\hline \multicolumn{5}{|c|}{ Experience of radiating pain } \\
\hline Yes & 62 & 66 & 194 & 322 \\
\hline No & 44 & 43 & 34 & 121 \\
\hline Total & 106 & 109 & 228 & 443 \\
\hline
\end{tabular}

the Korean conscription. The median age was 19 years old (ranging from the age of 19 to 33; 284 cases of 18 years old; 19 cases of 19 years old; and 233 cases of 20 years old and older). The examinees with medical certificates were 248 (56.2\%) cases (Table 2). Examinees who complained about their history of back pain were 422 (95.3\%) cases and radiating pain were 322 (72.7\%) cases. The rate of agreement for the experience of back pain or radiating pain with lumbar disc herniation was poor ( $\mathrm{K}$ coefficient $=0.222$ or 0.178 ).

The high economic class was composed of 130 cases, middle economic class 191 cases, and low economic class 122 cases. The physical grade according to economic status was shown in Table 3 . In the table without the consideration regarding the presence of a medical certificate, a total of 443 cases were relatively evenly distributed into the socioeconomic classes, and there was no significant statistical difference among the different classes $(p=0.290)$. Nevertheless, for the 249 cases in the presence of a medical certificate, the distribution by the socioeconomic classes was significantly different from the distribution of all 443 cases $(p=0.028)$. For the cases in the absence of a medical certificate, the distribution by the socioeconomic classes was not statistically different from the distribution of all 443 cases $(p=0.806$ ). The largest proportion of physical grade was grade 4-5 in the group with a medical certificate, and it reversed to grade 1-2 in the group without a medical certificate. The portion of physical grade 4-5 among high and middle economic class had a tendency of having a larger portion $(23.3 \%$ to $33.7 \%)$ with a medical certificate and a lower portion (5.1\% to $11.3 \%)$ without a medical certificate than the low economic status $(15.7 \%$ 
Table 3. Physical grade according to economic status

\begin{tabular}{|c|c|c|c|c|c|}
\hline \multirow{2}{*}{ Socioeconomic status } & \multicolumn{4}{|c|}{ Physical grade by Korean Military Service Law } & \multirow{2}{*}{$p$-value } \\
\hline & Grade 1-2 & Grade 3 & Grade 4-5 & Total & \\
\hline \multicolumn{5}{|c|}{ Total 443 cases without consideration of the presence of medical certificate } & 0.290 \\
\hline High economic class & $32(7)$ & $30(7)$ & $68(15)$ & $130(29)$ & \\
\hline Middle economic class & $44(10)$ & $41(9)$ & $106(24)$ & $191(43)$ & \\
\hline Low economic class & $30(7)$ & $38(9)$ & $54(12)$ & $122(28)$ & \\
\hline Total & $106(24)$ & $109(25)$ & $228(51)$ & $443(100)$ & \\
\hline 249 Cases with the presence of medical certificate & & & & & 0.028 \\
\hline High economic class & $6(2)$ & $12(5)$ & $58(23)$ & $76(31)$ & \\
\hline Middle economic class & $8(3)$ & $16(6)$ & $84(34)$ & $108(43)$ & \\
\hline Low economic class & $4(2)$ & $22(9)$ & $39(16)$ & $65(26)$ & \\
\hline Total & $18(7)$ & $50(20)$ & $181(73)$ & $249(100)$ & \\
\hline 195 Cases without the presence of medical certificate & & & & & 0.806 \\
\hline High economic class & $26(13)$ & $18(9)$ & $10(5)$ & $54(28)$ & \\
\hline Middle economic class & $36(18)$ & $25(13)$ & $22(11)$ & $83(43)$ & \\
\hline Low economic class & $26(13)$ & $16(8)$ & $16(8)$ & $58(30)$ & \\
\hline Total & $88(45)$ & $59(30)$ & $48(25)$ & $195(100)$ & \\
\hline
\end{tabular}

Values are presented as number (\%).

Table 4. Reasons of no medical certificate in the group with an experience of back pain and without the medical certificate

\begin{tabular}{lcccc} 
Reason of no medical certificate & No necessary & No chance to diagnosis & Financial problem & Total \\
\hline High economic class & $22(45.8)$ & $15(31.3)$ & $11(22.9)$ & $17(23.6)$ \\
Middle economic class & $36(50.0)$ & $19(26.4)$ & $22(39.3)$ & $72(100)$ \\
Low economic class & $16(28.6)$ & $18(32.1)$ & $50(28.4)$ & $176(100)$ \\
\hline Total & $74(42.1)$ & $52(29.5)$ & & $100)$ \\
\hline
\end{tabular}

Values are presented as number (\%).

and $8.2 \%$ according to a medical certificate).

The reason why they could not submit a medical certificate was found in the group of examinees who experienced back pain and in the absence of a medical certificate (Table 4). The reasons were that it was not necessary, there was no chance to diagnosis, and it was too expensive. According to socioeconomic class, the proportion of reasons was checked differently. For the group of high and middle economic status, the common reason for no medical certificate was unnecessary; for the group of low economic status, the reason was that it was financially unaffordable.

\section{Discussion}

Throughout history, socioeconomic status has been associated with health in many ways. The difference in socioeconomic status impacts the rates of mortality and morbidity for almost every disease and condition [4]. Since socioeconomic status is a powerful risk factor, the search for other etiological factors in disease end points is often regarded as a suspect unless the influence of socioeconomic status is controlled [5]. As a result, socioeconomic status has been almost universally relegated to the status of a controlled variable and has not been systemically studied as an important etiologic factor in its own right 
[5]. Socioeconomic status is a composite measure that typically incorporates economic status; social status; and work status [6]. The three indicators are interrelating but not fully overlapping variables. Often researchers use one of the indicators as the measure of socioeconomic status. In this study, the authors used monthly income as the sole indicator of socioeconomic status.

In the literature review, many reports were present about the relationship between socioeconomic status and disease. In coronary disease, higher socioeconomic status groups have a greater prevalence of risk factors than lower socioeconomic status groups [7]. Socioeconomic status appears to explain the differences in the prevalence of chronic diseases (hypertension, diabetes, heart condition, arthritis), it being greater in the group of lower economic status [8]. But, unfortunately, there are no reports about the relationship between socioeconomic status and the disease detection rate.

Furthermore, in regards to spinal disease, some reports present the relationship between socioeconomic status and disease. Likewise, for other diseases, socioeconomic factors are important risk factors for lumbar pain and disability [9]. But, most of these studies were based on the patients with office visits, medical administration or surgical treatments, and the patients were categorized according to their socioeconomic status. On the basis of existing studies, this study was the first to investigate the disease detection rate according to socioeconomic status.

In the Korean conscription system, examinees with a disease should have a medical certificate and medical record about the disease. The financial problem can interfere with the diagnosis of lumbar disc herniation by the high cost of radiologic imaging or physiologic studies. So, a medical certificate could present as one of the financial barrier of the conscripted examinees during the conscription. In our result, in the situation without the barrier of financial problems, the proportion of lumbar disc herniation was similar regardless of socioeconomic status $(p=0.290)$. However, the group with a medical certificate was differently proportioned according to their socioeconomic status $(p=0.028)$. This result means that the prevalence of lumbar disc herniation is constant without the consideration of socioeconomic status, but the detective rate is associated with socioeconomic status. As the results demonstrated, the detection rate increased with socioeconomic classes (Table 3). The examinees in the low economic class tend not to diagnosis although they experienced back pain and had moderate to severe lumbar disc herniation. The common reason for having no medical certificate was that it was not necessary in the group of high and middle economic status and that it was a financial problem in the group of low economic status (Table 4).

There were some limitations to this study. First of all, because the data was achieved from the military conscripted physical examination, only males were included in this study. A well-designed longitudinal prospective study with a larger number of general young populations including males and females should be included in order to overcome these limitations. Secondly, only computed tomography was used to diagnose lumbar disc herniation. Thus, some disease specific conditions could have been ignored in this study. Finally, socioeconomic status was not determined by only monthly incomes. Many factors such as education, work status, and occupation could interfere with socioeconomic status [6]. Despite its limitations, this study is meaningful to understand the interference of the detection rate by socioeconomic status.

The actual study at a general hospital is not easy, because of the financial problems. Fortunately, the authors had the opportunity to study the relationship between socioeconomic status and lumbar disc herniation without the examinee's financial problems in the Korean conscription. This recent study indicates that socioeconomic status is an important factor for detecting lumbar disc herniation, and this indication would not be localized to only lumbar disc herniation.

\section{Conclusions}

The prevalence of lumbar disc herniation is not different according to socioeconomic status, but the detection rate was affected by socioeconomic status; low detection rate in low economic status individuals and high detection rate in high economic class individuals. Therefore, socioeconomic status is one of the important factors for detecting lumbar disc herniation.

\section{Conflict of interest}

No potential conflict of interest relevant to this article was reported. 


\section{References}

1. Sorlie PD, Backlund E, Keller JB. US mortality by economic, demographic, and social characteristics: the National Longitudinal Mortality Study. Am J Public Health 1995;85:949-56.

2. Vafaei A, Rosenberg MW, Pickett W. Relationships between income inequality and health: a study on rural and urban regions of Canada. Rural Remote Health 2010;10:1430.

3. Christiansen M, Hansen CD, Glasscock D, Andersen $\mathrm{JH}$. Social inequality and health in adolescents. Ugeskr Laeger 2010;172:857-63.

4. Antonovsky A. Social class, life expectancy and overall mortality. Milbank Mem Fund Q 1967;45:31-73.

5. Adler NE, Boyce T, Chesney MA, et al. Socioeconomic status and health. The challenge of the gradi- ent. Am Psychol 1994;49:15-24.

6. Dutton DB, Levine S. Overview, methodological critique, and reformulation. In: Bunker JP, Gomby DS, Kehrer BH, editors. Pathways to health: the role of social factors. Melon park: The Henry J. Kaiser Family Foundation; 1989. p.29-69.

7. Stamatis G, Niederle N, Greschuchna D. Interdisciplinary concepts and long-term results after surgery of pulmonary metastases. Helv Chir Acta 1990;57:285-93.

8. Kington RS, Smith JP. Socioeconomic status and racial and ethnic differences in functional status associated with chronic diseases. Am J Public Health 1997;87:805-10.

9. Katz JN. Lumbar disc disorders and low-back pain: socioeconomic factors and consequences. J Bone Joint Surg Am 2006;88 Suppl 2:21-4. 